\title{
The effect of support group therapy on parentally bereaved adolescents: a randomized controlled trial
}

\begin{abstract}
Introduction/Objectives: Bereavement is considered to be the most stressful life event, and it becomes particularly distressing when it concerns the death of a parent, such an event is very traumatic to children. The literature suggests various interventions for bereaved children including individual counseling, music therapy, and support groups. The present study aims to examine the effect of a support group therapy for parentally bereaved youth on self concept, and symptoms of depression and anxiety.
\end{abstract}

Participants, Materials/Methods: The sample of the study have been collected from 4 governmental schools at Cairo, and the interventions given between September 2012 and July 2013, participants were students in grades 7th, and 8th who had experienced the death of one parent for 1 year or more prior to the study, all eligible participants who themselves and their parents gave consent to participate- were randomly assigned in 1:1 ratio to either supportive therapy intervention group or control group, the intervention group children were divided into groups each of 8-12 children which undergoes 12 weakly supportive group treatments led by the main investigators. The primary outcome was symptoms of anxiety, depression as well as self concept at 12 months; it was assessed at the baseline and 12 months after by three self-completed questionnaires: self concept scale, children's anxiety scale, and children's depression inventory. Analysis was by intention to treat.

Results: $60(50 \%)$ of participants were assigned to supportive therapy intervention group, and the other $60(50 \%)$ to control group, at 12 months we recorded differences between control and supportive therapy groups in child depression inventory scores $(19.2[\mathrm{SD} 5.55]$ vs $13.2[\mathrm{SD} 5.51] \mathrm{T}=4.25, \mathrm{P}=<0.001)$, children anxiety scale scores $(27.66[5.29]$ vs $24.61[4.62] \mathrm{T}=7.69, \mathrm{P}=<0.001)$ and self concept scale scores $(49.29[11.07]$ vs $58.18[4.55], \mathrm{t}=6.24, \mathrm{p}=<0.001)$. we also noticed significant differences between baseline and 12 months assessments in supportive therapy group, but not in control group on all outcome measures.

Conclusion: School based systematically delivered supportive therapy groups for bereaved youth found to be effective in reducing anxiety and depression symptoms, as well in enhancing their perceived self concept

Keywords: supportive group therapy, parentally bereaved children, parentally bereaved adolescents, grief intervention, depression, anxiety, self-concept
Volume 3 Issue 5 - 2017

\author{
Hesham M Abuhegazy,' Heba I Elkeshishi \\ 'Department of psychiatry and behavioral sciences,Al-Azhar \\ University faculty of medicine, Egypt \\ ${ }^{2}$ Department of psychology, El-menia University faculty of arts, \\ Egypt
}

Correspondence: Hesham Abuhegazy, Assistant professor of psychiatry, faculty of medicine for boys, Al-Azhar University faculty of medicine, Department of psychiatry and behavioral sciences, Cairo, Egypt, Tel 966530107236 ,

Email abuhegazy@gmail.com

Received: March 31, 2017 | Published: June 28, 2017
Abbreviations: SCS, self-concept scale; CAS, children's anxiety scale; CDI, children's depression inventory; ITT, intention-to-treat

\section{Introduction}

The loss of a close person, independent of the reason, is usually a traumatic experience. ${ }^{1}$ The death of a parent is always traumatic, ${ }^{2}$ it is the worst thing imaginable to a child, when it happens, the world is turned upside down, security is shaken, and the pain is overwhelming, this traumatic event is one that will affect a child profoundly for the rest of his or her life. ${ }^{3}$ It is estimated that one third of American children spends the first 18 years with only one parent, and one in 20 losses a parent by death before $18,{ }^{4}$ in UK $5 \%$ of children are bereaved of a parent before age of $16,{ }^{5}$ and almost 24000 of children and young adults experience the death of a parent each year. ${ }^{6}$ Grief is defined as an internal experience in reaction to the loss of something loved and valued. ${ }^{7}$ This loss can lead to the experience of losing control, and experiencing overwhelming emotions such as, fear, loneliness, loss of identity, and other difficult feelings. ${ }^{1}$ All people grieve differently; some need professional help while others are resilient in their loss and do not require special interventions. ${ }^{8}$

Disabling psychological responses to bereavement have received considerable attention in recent years. ${ }^{9}$ Studies have revealed many negative outcomes associated with childhood bereavement, the shortterm effects includes greater mental health problems, ${ }^{10}$ internalizing and externalizing problems, ${ }^{11}$ greater vulnerability for depression, ${ }^{12,13}$ anxiety, ${ }^{14-16}$ increased likelihood of substance abuse, ${ }^{17}$ loss of self esteem, ${ }^{11,18,19}$ self insufficiency, ${ }^{20}$ sadness, anger, loneliness, worries and contemplation of suicide, ${ }^{21}$ as well as behavioural problems, ${ }^{14,22}$ higher risk of criminal behavior, ${ }^{6}$ social withdrawal, ${ }^{20}$ poorer school enrollment, ${ }^{23}$ school underachievement, ${ }^{24}$ lower school grades and higher school failure ${ }^{25}$ with more engagement in paid employment, and self employment. ${ }^{23}$ Few studies have suggested that negative effects of childhood bereavement can last into adult life, ${ }^{26}$ a birth cohort quantitative study found long-term outcomes of early parental death particularly affects women and may include symptoms of depression, being smoker, with negative impacts on qualifications, and employment, ${ }^{5}$ while qualitative studies is seldom one recent 
narrative study have found that being orphaned in childhood have a negative impact in adulthood with regards to trust, relationships, self esteem, loneliness, and ability to express feelings. ${ }^{6}$

There is extensive debate about how best to support bereaved people, given the heterogeneity of perspectives on grief, support, and methodologies of evaluation. ${ }^{27}$ Research has identified several malleable child and family-level factors that can be important foci for clinical work with bereaved families, including providing education about the grief process, ${ }^{28,29}$ teaching parents and children techniques to increase children's self-esteem, ${ }^{18,30}$ adaptive control believes, ${ }^{31}$ improve child coping skills, ${ }^{32}$ and support for emotional expression, ${ }^{33}$ as well as teaching parents strategies to enhance the quality of the parent-child relationship,,$^{34,35}$ to increase positive family interactions, ${ }^{36,37}$ decrease parent psychological distress, ${ }^{38}$ and to reduce child exposure to negative life events. ${ }^{11,33}$

In general population, Bereavement groups are believed to be beneficial as preventive interventions from social and economic standpoints. Group interventions may also lessen the likelihood of development of complicated grief including risks of mental health problems such as major depression or anxiety. ${ }^{1}$ As well Interventions based on standard treatments for depression show minimal effects. ${ }^{39}$ Intervention models for helping the bereaved children and adolescents as well as families is not much, some interventions targets the children, some others targets the surviving parents or both ${ }^{40}$ some programs adopt individual interventions, and some intervenes through group therapies, the scope of interventions involves improving school environment, ${ }^{41}$ educational grief programs, ${ }^{42,43}$ peer group counselling programs,${ }^{44}$ outpatient group programs,${ }^{40}$ support group interventions, ${ }^{45,46}$ cognitive behavioural group therapies, ${ }^{47}$ and transitional events model which targets potentially malleable risk and protective factors, ${ }^{38,48}$ the interventions also included grief groups using guided imagery as tool to facilitate grief expression, ${ }^{49}$ or using music therapy to facilitate grief resolution..$^{50}$ Although attempts to evaluate the effectiveness of psychotherapies for bereaved persons have not reached conclusive results, quantitative meta-analyses reviews of bereavement interventions have failed to reach clear consensus, some reported week effect size as $(\mathrm{d}=0.11),{ }^{51}$ or $(\mathrm{d}=0.14),{ }^{52}$ others found the effect size is modest $(\mathrm{d}=0.43),{ }^{53}$ recent studies have yielded evidence for the relative efficacy of interventions with small to moderate effect sizes, and found interventions for symptomatic or impaired participants tended to show larger effect sizes than interventions for bereaved children and adolescents without symptoms,${ }^{54}$ and suggested that the studies that intervened in time-sensitive manner and those that implemented specific selection criteria produced better outcomes than investigations that did not attend to these factors, ${ }^{52}$ as well as under certain circumstances, bereavement interventions could possibly generate effect sizes comparable to those observed with therapies for other emotional and/or behavioural difficulties, ${ }^{55}$ while schools is an ideal venue for children's bereavement groups, as parents have trust in their children's schools which is usually a familiar and comfortable environment for the children and adolescents, the literature contain few examples of empirically evaluated school-based interventions to assist bereaved children, this study aims to investigate the efficacy of a 12-weeks school-based support group therapy for parentally bereaved children on reducing their depression and anxiety, and enhancing selfconcept.

\section{Subjects and methods}

The final sample of the study composed of 120 participants, 60 were allocated in the group therapy arm and 60 in the control arm.
157 students were a potential candidates (they were in the nominated classes and one of their parents were died one year or more before the onset of screening), they were screened for eligibility, 24(15.2\%) did not meet inclusion criteria. $133(74.7 \%)$ were eligible to participate, but $13(8.2 \%)$ declined or did not show interest to participate. $120(76.4 \%)$ were randomly assigned and compose the final sample size (37 from Abubakr Alseddik school, 25 from Alnahda school, 22 from Ahmed Orabi school, and 36 from Abbas El-Akkad school), according to randomization 60 participants allocated for supportive group therapy arm, and 60 participants allocated for non intervention arm. $100(83.3 \%)$ of 120 participants completed the 12 month follow up assessment. 8(6.6\%) moved from the schools, 4(3.3\%) lost to be contacted, $3(2.5 \%)$ did not attend the supportive group program regularly, and $5(4.16 \%)$ did not complete the 12 month follow up assessments.

The sample have been collected from 4 governmental schools at Cairo, 7 schools have been approached through an information letter and study enrolment form, 4 schools approved to participate in the study; the interventions given between September 2012 and July 2013. Participants were eligible if they met the following inclusion criteria: were male or female student attending his classes regularly; were in the $1 \mathrm{st}$ or $2^{\text {nd }}$ preparatory grade $\left(7^{\text {th }}\right.$ or $8^{\text {th }}$ grade), aged 11 15 years; and had experienced death of one parent one year or more prior to the study. Exclusion criteria were having organic or general medical impairment, having previous or ongoing history of psychiatric or addictive disorders or treatments, or not attending the school regularly.

Potential candidates were identified through school's administration and social workers, researchers did a screening interview with each participant to confirm eligibility for the study; all eligible candidates were approached personally and through letters to their parents describing the study procedures, and requesting them to sign the consent form, all participants who themselves and their parents gave consent to participate undergoes base line assessment and thin randomly assigned in 1:1 ratio to either supportive therapy intervention arm or control arm, the intervention arm children were divided into groups each of 8-12 children which undergoes 12 weakly school based supportive group treatments led by the main investigators. The group therapy sessions was done weekly for 120 minutes in the schools, the time schedule for each group was fixed and arranged with the students and each school administration. This was a prospective randomized controlled trial for the comparison of supportive group therapy for parentally bereaved adolescents with control non intervention group counterparts. The research ethics committee of department of psychiatry and behavioural sciences, AlAzhar University provided ethics approval for the study.

\section{Outcomes}

The primary outcome was symptoms of anxiety, depression as well as self concept; which was measured by three self-completed questionnaires: self concept scale, children's anxiety scale, and children's depression inventory. The assessments were done at the base line - before randomization-, and 12 months after randomization by research assistants masked to treatment allocation.

\section{Self-concept scale (SCS)}

Designed by Adel El-Ahwal ${ }^{56}$ to assess self concept in children. It consists of 80 items that require a 'yes' or 'no' response to indicate whether the statements describe how he or she feels. El-Ashwal ${ }^{56}$ reported that the scale is a valid research instrument and reliable. The 
reliability of the scale by using Test retest method was 0.89 and by split half Method was 0.921 .

\section{Children's anxiety scale (CAS)}

By Castanida et al. and translated to Arabic by Viola El-Beblawy. ${ }^{57}$ The scale is a children self-report instrument which consists of 53 items that requires' yes' or 'no' responses to measure anxiety among children, El-beblawy reported that the scale have a good psychometric properties in terms of validity, and reliability to be used to assess anxiety among Arabic speaking children.

\section{Children's depression inventory (CDI)}

Designed by Kaslow ${ }^{11}$ and translated by Gharib. ${ }^{58}$ The CDI is a 27 items self-report instrument designed to measure depression in children and adolescent aged 8 to 17 . Each item contains a threechoice responses format in the form of three statements reflecting its increasing severity of depression. Respondents are asked to select the statement from each group that describes him or her for the past 2 weeks. Gharib ${ }^{58}$ reported that the CDI is valid research instrument to determinate childhood depression. The internal consistency alphas, and split half method reliability was tested for our total sample and it reached consecutively $(0.79 \& 0.79)$ for self-concept scale, $(0.87$ $\& 0.90)$ for children's anxiety scale, and $(0.86 \& 0.87)$ for children's depression inventory.

\section{Treatment}

The bereaved children were exposed to the support group sessions for 12 weekly sessions for 2 hours each week. The groups were lead by the authors who has advanced training and experience in group work. All the participants were interviewed individually before starting group sessions to establish relationship, and discuss their perception about the experience of bereavement; both difficulties and what had been found helpful. The content of the sessions was selected to represent goals for bereaved support groups as suggested by Pennells and Smith. ${ }^{59}$

The first and second sessions set the atmosphere for the productive group experience. Participants became acquainted, established the group rules, and shared with each other who had died in their lives. Each participant created a folder in which to keep all the material for all the sessions. The folder had pictures drawn or taken from magazines that were representative of the person who died as well as the participants themselves. One of the goals identified by Pennells and Smith $^{59}$ is to increase the reality of the death. The activities in session $(1,2)$ began this process.

The objectives of sessions $(3,4)$ were to provide information about the feeling associated with the grieving process. This supported Pennells and Smith's ${ }^{59}$ goal of providing opportunities to voice fears and concerns and to acquire new knowledge. During the same session, participants created a list of all possible feelings that could be associated with the death of a parent and then talked about the ones that related to them. This provides opportunities to share fears and worries with others and to know that they were not alone. Sessions $(5,6)$ were designed to have the participants become knowledgeable about the grieving process by building on their feelings that had been identified in the previous sessions and learning how feelings occur at different times for different people as part of the grieving. This provided a means for the participants to begin to withdraw from the deceased parent, which is another goal identified by Pennells and Smith. ${ }^{59}$
Memories were the theme of the seventh and eight sessions. They were designed to provide participants with a safe environment to talk about their deceased parents. Each participant brought in and/ or shares a memory about his or her deceased parent. This supported Pennells and Smith ${ }^{59}$ goals of withdrawing from the parent, increasing the reality of death, and freely talking about his or her feeling related to death. The objectives of the sessions $(9,10)$ were to encourage and provide practice in ways to discuss grief with other members of their families. Participants were asked to draw a picture of their families before and after the death of a parent and to identify major differences other than the absence of the parent. The participants then shared ways they had previously found successful in discussing their feeling with family members as well as why they were reluctant to do so. They then developed a plane to try to share feeling with members of their families and practiced this with each other. The activities in sessions $(9,10)$ supported Pennells and Smith ${ }^{59}$ final goal which is to have participants readjust and to adapt to new family roles.

During sessions $(11,12)$ participants were able to develop appropriate ways to respond to the feeling of grief through discussions of all they had learned and experienced over the last weeks. Throughout the activities of all sessions, there was an emphasis on the creating a safe environment to share feelings, concerns, and hopes which has been identified as a need for bereaved children. Comments on the sessions: After the final support group sessions, the subject were again seen individually by the authors in order to facilitate termination of the support group sessions, we used the questionnaire to assess the perception of the value of group meetings designed by Quarmby ${ }^{44}$ to discover the perception of participants concerning the value of a different aspects of the support group session experience. Subjects felt that the experience of listening to others had been helpful to them and to the person talking. They also felt that they were better understood and the sessions make a definite difference to their lives.

During the first and second sessions, self disclosure was slight, but by the third session mutual trust had clearly begun to develop, and the participants were able to talk about difficulties or painful aspects of their bereavement experiences. The development of the ability to make verbal disclosures of areas of painful experience was not the only achievement of these bereaved children. The skill of active listening is one that is normally considered difficult to acquire, and yet it seemed to come naturally to these bereaved children. There was a high degree of attentiveness during these meetings (95\%), and an atmosphere of mutual empathy was noticeably generated. This is something that cannot be demonstrated but it was there and to an extent that seemed to the group leader to mark a notable achievement by the group members. The members of the support group supported each other and some of them could by a few well chosen works convey a full sense of understanding and encouragement to someone else in the group.

\section{Statistical analysis}

Data were tested for normality using Kolmogrov and Smirnove test. Categorical variables were presented as number and percentage while numerical variables were presented as mean and standard deviation. $\mathrm{T}$ - Test was used for comparison between means of control group and intervention group, whereas the $\chi 2$ test was used to assess differences between Categorical variables. The analysis was performed based on the intention-to-treat (ITT) protocol. All analysis was performed with the Statistical Program for Social Sciences software (SPSS, Inc. Version 21.0, Chicago, IL, USA). A two-sided $\mathrm{P}<0.05$ was taken as statistically significant (Figure 1). 


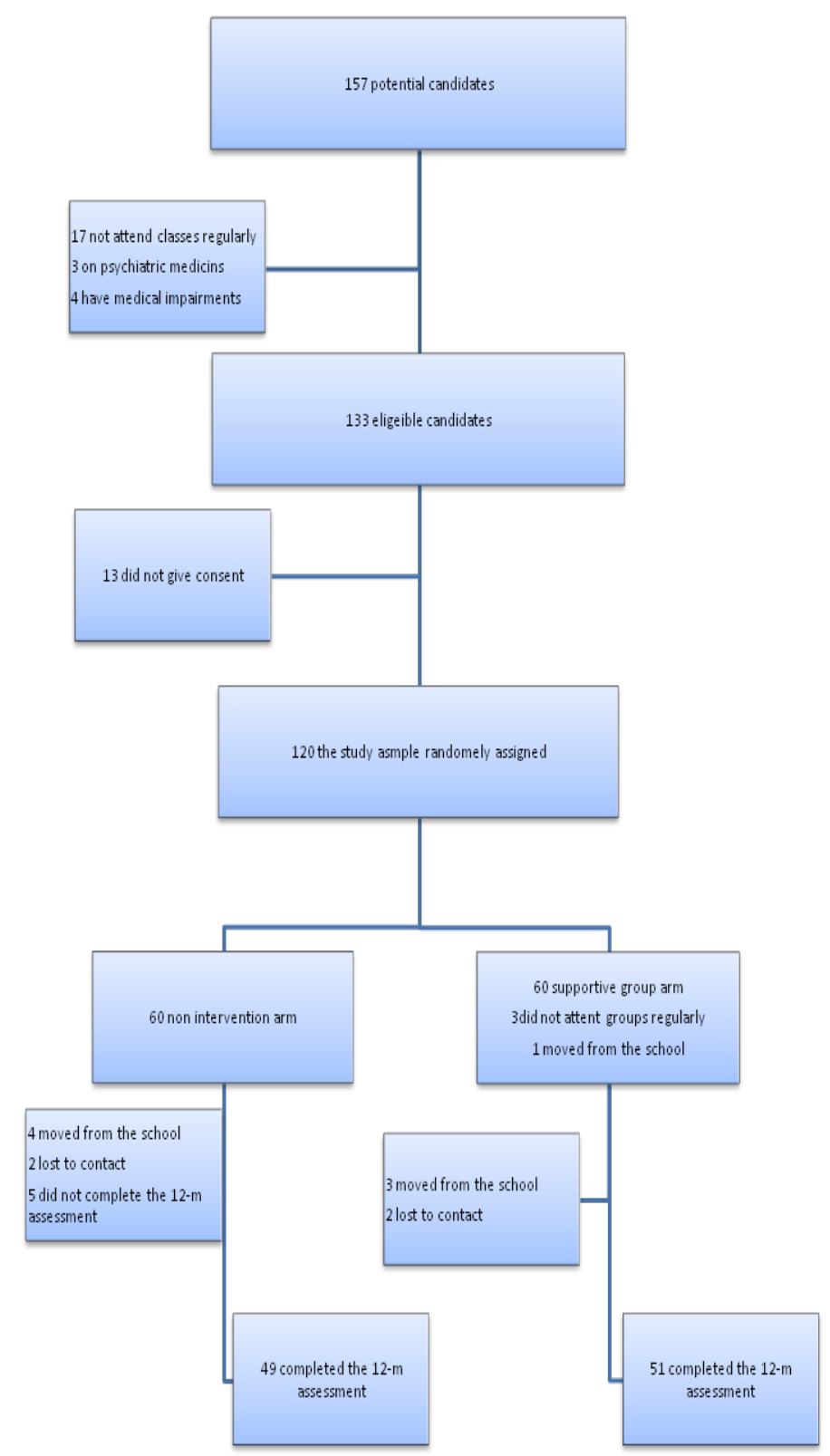

Figure I Intention-to-treat (ITT) protocol.

\section{Results}

Table 1 shows the demographics of the sample, mean age was 12.8 years ( $\mathrm{SD}=2.2), 69(57.5 \%)$ of participants were girls, $76(63.3 \%)$ have one or two siblings, $95(79.2 \%)$ live with the surviving single parent, and the surviving parent was the mother in $72(60 \%)$ of the participants. Baseline psychological assessments revealed no statistical differences between intervention and non-intervention groups on any of the outcome measures, as noticed in self assessment scale [46.81(7.25) vs 49.77(11.18), $\mathrm{T}=1.25, \mathrm{p}>0.05]$, children's anxiety scale [30.41(4.59) vs $28.54(5.14) . \mathrm{T}=1.55, \mathrm{p}>0.05$ ], and children's depression inventory [21.98(6.43) vs 20.2(5.82), $\mathrm{T}=1.16, \mathrm{p}>0.05]$.

The comparison between 12 months assessments of supportive group therapy arm, and non-intervention arm Table 2 shows significant differences between-groups in favour of supportive group therapy arm on all outcome measures as noticed in self concept scale [58.18(4.55) vs 49.29(11.07), T=6.24, $\mathrm{p}<0.01]$, children's anxiety scale [24.61(4.62) vs 27.66(5.29), $\mathrm{T}=7.69, \mathrm{p}<0.01]$, and children's depression inventory [12.96(5.29) vs 19.37(5.61), $\mathrm{T}=5.09, \mathrm{p}<0.01]$, We recorded within-group changes between baseline and 12 months assessments in supportive group arm as shown in the improvement on self concept scale [46.81(7.25) vs 58.18(4.55)], and reduction on both children's anxiety scale [30.4(4.59) vs 24.6(4.62)], and children's depression inventory [21.98(6.43) vs 12.96(5029)], however nonintervention arm did not show within-group changes between base line and 12 months assessments on either of self concept scale [49.77(11.18) vs 49.29(11.07)], children's anxiety scale [28.54(5.14) vs 27.66(5.29)], or children's depression inventory [20.2(5.82) vs 19.37(5.61)]. 
Table I Baseline characteristics of participants

\begin{tabular}{|c|c|c|c|c|}
\hline \multirow[b]{2}{*}{ Age (years) } & \multirow{2}{*}{$\begin{array}{l}\text { Total study sample }(\mathrm{n}=\mid \mathbf{2 0}) \\
2.8(2.2)\end{array}$} & \multirow{2}{*}{$\begin{array}{l}\text { Supportive group arm }(n=60) \\
12.9(1.9)\end{array}$} & \multicolumn{2}{|c|}{ Non intervention arm $(n=60)$} \\
\hline & & & $12.7(2.1)$ & $T=1.12$ \\
\hline \multicolumn{5}{|l|}{ Sex } \\
\hline Boys & $51(42.5 \%)$ & $26(43.3 \%)$ & $25(41.6 \%)$ & $X^{2}=0.03$ \\
\hline girls & $69(57.5 \%)$ & $34(56.6 \%)$ & $35(58.3 \%)$ & \\
\hline \multicolumn{5}{|l|}{ Number of siblings } \\
\hline 0 & $9(7.5 \%)$ & $5(8.3 \%)$ & $4(6.6 \%)$ & $X^{2}=0.58$ \\
\hline $1-2$ & $76(63.3 \%)$ & $36(60 \%)$ & $40(66.6 \%)$ & \\
\hline 3 or More & $35(29.1 \%)$ & $19(31.6 \%)$ & $16(26.6 \%)$ & \\
\hline \multicolumn{5}{|l|}{ Living situations } \\
\hline Single Parent & 95 (79.2\%) & 49 (81.6\%) & $46(76.6 \%)$ & $X^{2}=0.62$ \\
\hline Parent \& step Parent & 17 (14.2\%) & 7 ( $11.6 \%)$ & $10(16.6 \%)$ & \\
\hline Other & $8(6.6 \%)$ & $4(6.6 \%)$ & $4(6.6 \%)$ & \\
\hline Surviving parent & & & & $X^{2}=0.56$ \\
\hline Father & $48(40 \%)$ & $26(43.3 \%)$ & $22(36.6 \%)$ & \\
\hline Mother & $72(60 \%)$ & $34(56.6 \%)$ & $38(63.3 \%)$ & \\
\hline \multicolumn{5}{|c|}{ Baseline psychometric assessments } \\
\hline SCS & $44.12(14.11)$ & 46.81 (7.25) & 49.77 (II.18) & $\mathrm{T}=1.25$ \\
\hline CAS & 31.62 (6.42) & $30.4 I$ (4.59) & $28.54(5.14)$ & $\mathrm{T}=1.55$ \\
\hline CDI & $23.08(10.27)$ & $21.98(6.43)$ & $20.2(5.82)$ & $\mathrm{T}=1.16$ \\
\hline
\end{tabular}

Data are mean (standard deviation) unless otherwise specified.

SCS: Self Concept Scale; CAS: Children's Anxiety Scale; CDI: Children's Depression Inventory; T test used for continuous variables and X2 for test for dichotomous variables, all $p$ values $>0.05$.

Table 2 Psychological outcome variables at baseline and 12 months follow up

\begin{tabular}{|c|c|c|c|}
\hline & Supportive group arm & Non intervention arm & $\mathbf{T}$ \\
\hline \multicolumn{4}{|c|}{ Self concept scale } \\
\hline Baseline & $46.81(7.35)$ & $49.77(11.18)$ & 1.25 \\
\hline I2-Months & $58.18(4.55)$ & $49.29(11.07)$ & $6.24 * *$ \\
\hline \multicolumn{4}{|c|}{ Children's anxiety scale } \\
\hline Baseline & $30.4 I(4.59)$ & $28.54(5.14)$ & 1.55 \\
\hline I2-Months & $24.61(4.62)$ & $27.66(5.29)$ & $7.69 * *$ \\
\hline \multicolumn{4}{|c|}{ Children's depression inventory } \\
\hline Baseline & $21.98(6.43)$ & $20.2(5.85)$ & 1.16 \\
\hline I2-Months & I $2.96(5.29)$ & $19.37(5.6 \mathrm{I})$ & $5.09 * *$ \\
\hline
\end{tabular}

Data are mean (standard deviation) unless otherwise specified. ${ }^{* *}=p<0.01$

\section{Discussion}

The results of this randomized controlled trial suggest that supportive group is effective in improving the self concept, as well in reducing depressive and anxiety symptoms among parentally bereaved children, the analyses demonstrated that at 12-months follow up there was significant differences between supportive group candidates and non-intervention candidates on all outcome measures. this results is consistent with the positive results of most interventions that aims to help bereaved children as peer group counselling program by Quarmby, ${ }^{44}$ outpatient group program by Schoemann et al., ${ }^{40}$ educational grief program by Goldberg et al., ${ }^{43}$ creating supportive school environment to bereaved children by McGlaufen (1998), as well as grief groups which uses guided imagery by Glazer, ${ }^{49}$ and music therapy by Bright $^{50}$ which all revealed positive results in helping children and adolescents to cope with their bereavements, and reducing their depressive, anxiety symptoms as well as their behavioral difficulties. However our results contrasted that of Huss ${ }^{46}$ which found 6-sessions supportive group for 17 parentally bereaved middle school children did not show significant changes in reducing depressive symptoms, or problematic behavior, or improving their self-esteem., we believe that small sample size, too short duration of 
therapy, as well lack of randomization in Huss trial may contribute for the negative results.

we noticed also that drop out from support group arm was 3 out of $60(5 \%)$, this $95 \%$ compliance and commitment rate on 12 -session school based support group is a very high compliance rate, this along with positive feedback from participants and positive outcome of the intervention may be mediated through the nature of support group which does not require structured learning activities which be inherently stress producing, the lower demands of the support group may be responsible for the lower distress level, and the improved positive self concept, sharing experiences also is a crucial component of the supportive groups which help to heal the since of isolation, alienation and loneliness.

\section{Strengths and limitations}

our study have its own strengths like the well organized structure of supportive group intervention, the long enough follow-up period which points to persistent effect of the intervention, as well discreet outcome measures. However the study have its own limitations., first was the subjective nature of outcome measures, the results could hold more validity if it had measured with other rates measures of behavior like parent's, or teacher's-rated instruments, if used clinical diagnoses measures like structured or semi structured interviews to substrate subjects with clinical depression or anxiety, or if used subjective measures of functioning like school performance measures. Second is the lack of adjustment for possible mediating/moderating factors like gender, method of death of the parent, life situations, and other stressful life events, however proper randomization and good sample size could alleviate the effect of intervening variables.

\section{Conclusion}

The results of the present study showed that school-based supportive group program significantly reduces anxiety and depression, and enhances self-concept among parentally bereaved middle school children. The findings suggest that psychological benefits sustained for 12-months follow-up. Overall this study provides an empirical support for the efficacy of a supportive group intervention tailored to help parentally bereaved children and adolescents.

\section{Acknowledgments}

We thank the schools and students who participated in this trial, the school administrators, social workers, research team Heba Ali, Yaser Mohamed, Mansour Abolleil, and Mayar Hany. We acknowledge the support of dr Noha Saleh, and Dr. Adel sultan in data processing, and statistical analysis.

\section{Conflict of interest}

We declare no competing interests.

\section{References}

1. Näppä U, Lundgren AB, Axelsson B. The effect of bereavement groups on grief, anxiety, and depression - a controlled, prospective intervention study. BMC Palliat Care. 2016;15:58 p.

2. Auman MJ. Bereavement support for children. $J$ Sch Nurs 2007;23(1):34-39.

3. Grace H Christ. Healing children's grief. New York: Oxford university press; 2000. $288 \mathrm{p}$.

4. Hayes RC. Coping with loss: A developmental approach to helping children and youth. Counselling and human development. 1984;17(3):1-12.
5. Parsons S. Long-term impact of childhood bereavement: preliminary analysis of the 1970 British cohort study (BCS70). Childhood wellbeing research centre, London, UK; 2011.

6. Ellis J, Dowrick C, Llioyd-williams M. The long-term impact of early parental death: Lessons from a narrative study. $J R$ Soc Med. 2013;106(2):57-67.

7. D'Antonio J. Caregiver grief and anticipatory mourning. J Hosp Palliat Nurs. 2014;16(2):99-104.

8. Love AW. Progress in understanding grief, complicated grief, and caring for the bereaved. Contemp Nurse. 2007;27(1):73-83.

9. Bryant RA, Kenny L, Joscelyne A, et al. Treating Prolonged Grief Disorder A Randomized Clinical Trial. JAMA Psychiatry. 2014;71(12):13321339.

10. Haine RA, Wolchik SA, Sandler IN, et al. Positive parenting as a protective resource for parentally bereaved children. Death Stud. 2006;30(1):1-28.

11. Thompson MP, Kaslow NJ, Price AW, et al. Role of secondary stressors in the parental death-child distress relation. J Abnorm Child Psychol. 1998;26(5):357-366.

12. Mack KY. Childhood family disruptions and adult well-being: The differential effects of divorce and parental death. Death Stud. 2001;25(5):419-443.

13. Harrison L, Harrington R. Adolescent's bereavement experiences. Prevalence, association with depressive systems, and use of services. $J$ Adolesc. 2001;24(2):159-169.

14. Kaffman M, Elizur E. Children's bereavement reactions following death of the father. International journal of family therapy. 1979;1(3):203229 .

15. Hindle D. Doubly bereaved. Journal of child psychotherapy. 1996;22(2):261-278.

16. Worden JW. Children and grief: when a parent dies. New York: Guilford press; 1996. $225 \mathrm{p}$.

17. Sweeting H, West $\mathrm{P}$, Richrds $\mathrm{M}$. Teenage family life, lifestyles, and life chances: Associations with family structure, conflict with parents and joint family activity. Int J Low Policy Family. 1998;12(1):15-46.

18. Haine RA, Ayers TS, Sandler IN, et al. Locus of control and self-esteem as stress-moderators or stress-mediators in parentally bereaved children. Death Stud. 2003;27(7):619-640.

19. Fristad M, Glickerman A, Verducci J, et al. Study V: Children's Interview for Psychiatric Syndromes (ChIPS): psychometrics in two community samples. J Child Adolesc Psychopharmacol. 1998;8(4):237-245.

20. Worden JW, Silverman PR. Parental death and the adjustment of school-age children. $J$ death dying. 1996;33(2):91-102.

21. McClatchey IS, Wimmer JS. Coping with parental death as seen from the perspective of children who attended a grief camp. Qualitative social work. 2014;13(2):221-236.

22. Tremblay GC, Israel AC. Children's adjustment to parental death. Clinical psychology: science and practice. 1998;5(4):424-438.

23. Rozana Himaz. Impact of parental death in middle childhood and adolescence on child outcome. J Afr Econ. 2013;22(3):463-490.

24. Abdelnoor A, Sheila Hollins. The effect of childhood bereavement on secondary school performance. Educ psycho pract. 2004;20(1):43-54.

25. Berg L, Rosita M, Saarla J, et al. Parental death during childhood and subsequent school performance. Pediatrics. 2014;133(4):682-689.

26. Marcoux Y, Kiely M. Early loss and adult personality. Bereavement care. $1985 ; 4(1): 3-11$. 
27. Spence S, Smale U. Group work with bereaved people: developing person-centered practice. Journal of Person-Centered \& Experiential Psychotherapies. 2015;14(1):3-17.

28. Corr CA. Children's understanding of death: striving to understand. In: Doka KJ, editor. Child mourning: mourning children. Hospice foundation of America, Washington, USA; 1995. p. 3-16.

29. Lohnes KL, Katler N. Preventive intervention groups for parentally bereaved children. Am J Orthopsychiatry. 1994;64(4):594-603.

30. Wolchik SA, Tein JY, Sandler IN, et al. Stressors, quality of child-caregiver relationship, and children's mental health problems after parental death: The mediating role of self-esteem beliefs. J Abnorm Child Psychol. 2006;34(2):221-238.

31. Sandler I, Ayers T, Twohey J, et al. Family bereavement program group leader intervention manual for child program. Arizona state university program for prevention research, Tempe, USA; 1996.

32. Sandler IN, Tein JY, Metha P, et al. Coping efficacy and psychological problems of children of divorce. Child Dev. 2000;71(4):1099-1118.

33. Tein JY, Sandler IN, Ayers TS, et al. Mediation of the effects of the family bereavement program on mental health problems of bereaved children and adolescents. Prev Sci. 2006;7(2):179-195.

34. Kwok OM, Haine RA, Sandler IN, et al. Positive parenting as a mediator of the relations between caregiver's psychological distress and children's mental health problems of parentally bereaved children. J Clin Child Adolesc Psychol. 2005;34(2):260-271.

35. Saldinger A, Cain AC, Porterfield K, et al. Facilitating attachment between school-aged children and dying parent. Death Stud. 2004;28(10):915-940.

36. Raveis V, Siegel K, Karus D. Children's psychological distress following the death of a parent. Journal of youth and adolescence. 1999;28(2):165-180.

37. Saler L, Skolnick N. Childhood parental death and depression in adulthood: roles of surviving parent and family environment. Am J Orthopsychiatry. 1992;62(4):504-516.

38. Sandler IN, Ayers TS, Wolchik SA, et al. The family bereavement program: Efficacy evaluation of the theory based prevention program for parentally bereaved children and adolescents. J Consult Clin Psychol. 2003;71(3):587-600.

39. Wenn J, O’Connor M, Breen LJ, et al. Efficacy of metacognitive therapy for prolonged grief disorder: protocol for a randomised controlled trial. BMJ Open. 2015;5(12):007221e.

40. Schoeman L, Kreitzman R. Death of a parent: Group intervention with bereaved children and their caregivers. Psychoanalysis and psychotherapy. 1997;14(2):221-245.

41. Gunther M, Crandles S, Williams G, et al. A place Called hope: Group psychotherapy for adolescents of parents with HIV/Aids. Child welfare. 1998;77(2):251-271.
42. Frydenberg E, Muller D, Ivens C. The experience of loss: Coping and the seasons for growth program. The educational and developmental psychologist. 2006;23(1):45-68.

43. Goldberg FR, Leyden HD. Left and left out: teaching children to grieve through a rehabilitation curriculum. Professional school counselling. 1998;2(2):123-127.

44. Quarmby D. Peer group counselling with bereaved adolescents. British journal of guidance and counselling. 1993;21(2):196-211.

45. Mitchill A, Wesner S, Garand L, et al. A support group intervention for children bereaved by parental suicide. J Child Adolesc Psychiatr Nurs. 2007;20(1):3-13.

46. Huss S, Ritchie M. Effectiveness of a group for parentally bereaved children. The journal for specialists in group work. 1999;24(2):186-196.

47. Boelen P, de Keijser J, Vna den Hout M, et al. Treatment of complicated grief: A comparison between cognitive behavioral therapy and supportive counseling. J Consult Clin Psychol. 2007;75(2):277-284.

48. Sandler IN, West SG, Baca L, et al. Linking empirically based theory and evaluation: the family bereavement program. Am J Community Psychol. 1992;20(4):491-521.

49. Glazer HR. Expression of children's grief. A qualitative study. Int J play therapy. 1998;7(2):51-65.

50. Bright R. Music therapy in grief resolution. Bull Menninger Cli. 1999;63(4):481-498.

51. Kato P, Mann T. A synthesis of psychological interventions for the bereaved. Clin Psychol Rev. 1999;19(3):275-296.

52. Currier JM, Holland JM, Neimeyer RA. The effectiveness of bereavement intervention with children: a meta-analytic review of controlled outcome research. J Clin Child Adolesc Psychol. 2007;36(2):253-259.

53. Allumbaugh DL, Hoyt WT. Effectiveness of grief therapy: A meta-analysis. Journal of counseling psychology. 1999;46(3):370-380.

54. Rosner R, Kruse J, Hagl M. A meta-analysis of interventions for bereaved children and adolescents. Death Stud. 2010;34(2):99-136.

55. Currier JM, Neimeyer RA, Berman JS. The effectiveness of therapeutic interventions for bereaved persons: a comprehensive quantitative review. Psychol Bull. 2008;134(5):648-661.

56. Al-Ashool Adel. Scale of self concept in children. The Anglo Egyptian Library, Cairo, Egypt; 1984

57. Beblawi Viola. Anxiety anxiety for children. The Anglo Egyptian Library, Cairo, Egypt; 1987.

58. Ghareeb Abdel Fattah. Depression (d) for the young. Arab Renaissance House, Cairo, Egypt; 1995.

59. Pennels M, Smith SC. The forgotten mourners: Guidelines for working with bereaved children. Kingsley, Bristol, UK; 1995. 60 p. 